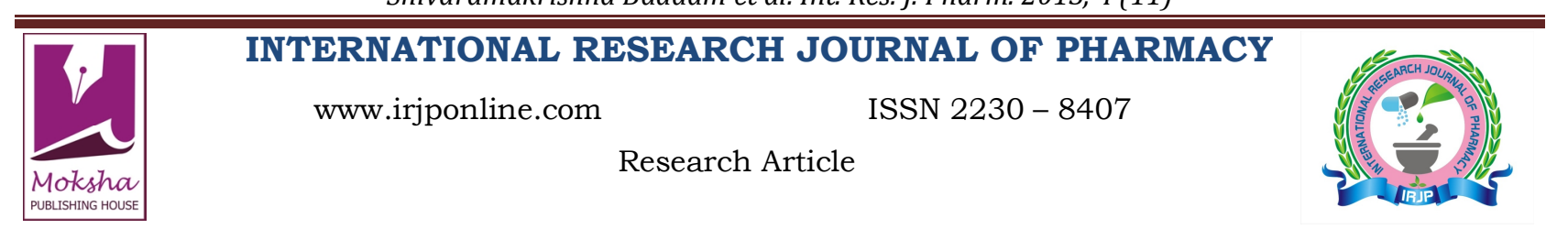

\title{
FORMULATION AND EVALUATION OF FAST DISSOLVING TABLETS OF OFLOXACIN BY DIRECT COMPRESSION METHOD
}

Shivaramakrishna Baddam ${ }^{1}$, Sreedhar Bandari ${ }^{2}$, G.B Chaithanya ${ }^{1}$

${ }^{1}$ K.M College of pharmacy, Madurai, Tamil Nadu, India

${ }^{2}$ Research and Development, Hetero drugs ltd, Hyderabad, India

*Corresponding Author Email: shivaramakrishna777@gmail.com

Article Received on: 10/10/13 Revised on: 01/11/13 Approved for publication: 17/11/13

DOI: 10.7897/2230-8407.041118

IRJP is an official publication of Moksha Publishing House. Website: www.mokshaph.com

(C) All rights reserved.

\section{ABSTRACT}

Ofloxacin is a broad-spectrum, synthetic fluoroquinolones antibacterial agent for oral administration. The bioavailability of ofloxacin in the tablet formulation is approximately $98 \%$. It is extremely bitter in taste, water insoluble drug. It is used to treat variety of infections. The purpose of the present research work was to formulate and evaluate the fast dissolving tablets of ofloxacin by direct compression method using different super disintegrants like PGS (pre gelatinized starch), SSG (sodium starch glycolate), PVPP (ploy vinyl poly pyrrolidone) in different concentrations $5 \%$, $7.5 \%, 10 \%$. FT-IRspectroscopy was used to investigate the physical characteristics of the complex. The blend was evaluated for angle of repose, bulk density, tapped density, carr's index, hausner ratio. The tablets were evaluated for weight variation, hardness, friability, disintegration time, water absorption ratio, wetting time, drug content uniformity and in vitro dissolution. Tablet formulated with $10 \%\left(\mathrm{~F}_{9}\right)$ of PVPP showed low disintegration time $(8 \pm 2)$, wetting time $(4.3 \pm 0.3)$, friability than the other batches. The $\%$ cumulative release of drug from tablet $\left(\mathrm{F}_{9}\right)$ was found to be more than $87 \%$ within 10 minutes. It was concluded from the study that ofloxacin may improve patient compliance especially pediatric and geriatric patients and increase the efficacy of drug for treating infections.

Keywords: Fluoroquinolone, fast dissolving tablets, ofloxacin, superdisintegrants.

\section{INTRODUCTION}

The oral route of drug administration is the most important method for administering drugs for systemic effects. Except in certain cases the parenteral route is not routinely used for self-administration, e.g. Insulin. The topical route of administration has only recently been employed to deliver drugs to the body for systemic effects. The parenteral route of administration is important in treating medical emergencies in which the subject is comatose or cannot swallow. Nevertheless it is probable that at least $90 \%$ of all drugs used to provide systemic effect are administered by the oral route. When a new drug is discovered one of the first questions a pharmaceutical company asks is whether or not the drug can be effectively administered for its intended effect by the oral route. Of drugs that are administered orally, solid oral dosage forms represent the preferred class of products. Tablets and capsules represent unit dosage forms in which usual dose of a drug has been accurately placed.

\section{Tablets}

Tablets $^{1}$ are solid preparation each containing a single dose of one or more active ingredients and are obtained by compressing uniform volumes of particles. The objective of the design and manufacture of the compressed tablet is to deliver orally the correct amount of drug in the desired location and to have its chemical integrity protected to the point. Tablets may vary in size, shape, weight, hardness, thickness, and disintegration characteristics and in other aspects, depending upon the intended use of the tablets and their method of manufacture.

\section{Types of Tablets}

1. Tablets ingested orally. e.g. standard compressed tablets, enteric coated tablets, delayed release tablets and mouth dissolving tablets

2. Tablets used in the oral cavity. e.g. buccal and sublingual tablets,
3. Tablets used to prepare solution. e.g. effervescent tablets

4. Tablets administered through other routes. e.g. vaginal tablets and implants ${ }^{1}$

\section{Historical Development of Fast Dissolving Tablets}

Difficulty in swallowing (Dysphagia) is a common problem in all age groups, especially the elderly and pediatrics, because of physiological changes associated with these age groups. It is common to see those afflicted carrying a small device with them, which is used for crushing tablets, enabling easy ingestion. Other categories that experience problems using conventional oral dosage forms include are the mentally ill, uncooperative and nauseated patients, those with conditions of motion sickness, sudden episodes of allergic attack and coughing. Sometimes, it may be difficult to swallow conventional products due to unavailability of water. These problems led to the development of a novel type of solid oral dosage form called mouth-dissolving tablets, which disintegrate and dissolve rapidly in saliva without the need of the water. They are also known as fast dissolving tablets, melt-in-mouth tablets, rapimelts, porous tablets, orodispersible, quick dissolving or rapidly disintegrating tablets. Since 1986 when the Zydis ${ }^{\circledR}$ lyophilized, fast-dissolving dosage forms were first introduced, a number of other fastdissolving formulations were developed, and the technology is still improving. Using the concept of Gregory et $a l^{2}$, Scherer has patented the Zydis technology. Using the freeze drying process, this technology converts the mixture of active ingredient and water dispersible carrier materials into open matrix network that disintegrates rapidly. The network is highly porous solid form which allows rapid penetration of liquid and facilitates quick disintegration of the dosage unit. The freeze-drying approach produces the fastest dissolving tablets, but the process is expensive, and the resulting tablets are mechanically weak. The other most widely used method to manufacture these tablets is via regular compression that can produce tablets with higher mechanical strengths. The 
disintegration or melting time of the compressed tablets is not as fast as the freeze-dried dosage forms, but the compressed tablets provide many advantages, such as high mechanical strength facilitating their handling and processing. The technology of the compressed tablets is also making major improvements, producing tablets that can melt within several seconds in the mouth. The fast-melting tablets present the combined benefits of a liquid formulation and a solid dosage form. They are easy to handle and ingestible as a liquid dosage form. An ideal fast-melting tablet should possess the following characteristics. The tablet should melt or disintegrate in the mouth within 60 seconds. The tablets should also be mechanically strong for easier handling, and the production cost should be similar to that of conventional tablets. The use of existing tablet machinery and procedures dictates the low production cost and has another advantage of producing mechanically strong tablets. The ideal fast-melting tablets should also be less sensitive to humidity, thus allowing multi-tablet packaging.

\section{Definition}

Oro dispersible tablets are uncoated tablets intended to be placed in the mouth where they disperse rapidly before being swallowed ${ }^{3}$.

\section{Advantages of Fast Dissolving Dosage Form}

- Ease of administration for patients who are mentally ill, disabled and uncooperative

- Requires no water intake.

- Quick disintegration and dissolution of dosage form.

- Overcomes unacceptable taste of the drugs

- Can be designed to leave minimal or no residue in the mouth after administration and also to provide a pleasant mouth feel.

- Allows high drug loading.

- Faster onset of action

- Convenient - ideal dosage form when fast relief required, for example, pain relief, migraine, or allergy

- New business opportunities; line extension exclusivity of product promotion and patient life extension ${ }^{2}$

\section{Desired Criteria for Mouth Dissolving Drug Delivery} System

Mouth Dissolving Tablet should-

- Not require water to swallow, but it should dissolve or disintegrate in the mouth in matter of seconds.

- Be compatible with taste masking.

- Be portable without fragility concern.

- Have a pleasing mouth feel.

- Leave minimal or no residue in the mouth after oral administration.

- Exhibit low sensitivity to environmental conditions as humidity and temperature.

- Allow the manufacture of tablet using conventional processing and packaging equipment at low cost

- Pre gastric absorption can result in improved bioavailability and as a result of reduced dosage, improved clinical performance through a reduction of unwanted effects ${ }^{4}$.

\section{MATERIALS AND METHODS}

Table 1: Materials

\begin{tabular}{|c|c|}
\hline Materials & Source \\
\hline Ofloxacin & Dr. Reddy's Laboratories \\
\hline MCC & Lobachemiepvt .ltd \\
\hline Mannitol & E.Merk (India ) ltd \\
\hline Magnesium stearate & Lobachemiepvt .ltd \\
\hline Talc & Indian research products \\
\hline PVPP & Sigma- aldrichchemie GmbH \\
\hline PGS & S.A chemicals \\
\hline Sodium starch glycolate & LobachemiePvt .Ltd \\
\hline Ammonium chloride & S.D. Fine Chemicals Pvt. Ltd. \\
\hline
\end{tabular}

Table 2: Instruments

\begin{tabular}{|c|c|}
\hline Equipment & Model/Company \\
\hline UV visible spectrophotometer & JASCO V-530 \\
\hline FT-IR spectrophotometer & FT-IR 8201 PC \\
\hline Digital balance & Denver instruments XP-300 \\
\hline Balance & Dona 200-D \\
\hline Disintegration apparatus & Remi equipment \\
\hline Dissolution apparatus & Eletrolab \\
\hline Friabilator & Excel enterprises \\
\hline Tablet punching machine & RimekMinipress I \\
\hline Hardness tester & Pfizer \\
\hline
\end{tabular}

Drug: Ofloxacin

Characteristics

Ofloxacin is off-white to pale yellow crystalline powder ${ }^{5-8}$.

\section{Solubility}

Slightly soluble in water, soluble in glacial acetic acid, slightly soluble to soluble in methylene chloride, slightly soluble to soluble in methanol.

\section{Ingredients}

- Rapid disintegrants - PGS, PVPP, Sodium starch glycolate, Disintegrant helps in dispersing the drug particle

- Sweetening agent and diluent - Mannitol it helps to impart mouth feel due to its negative heat of solubilzation

- Directly compressible agent - MCC

- Lubricants - Talc and Magnesium stearate

\section{Characterization of Ofloxacin Fast Dissolving Tablets} Fourier Transform infrared Spectroscopy (FT-IR)

The IR spectra of Ofloxacin and Ofloxacin in different carriers (PVPP, PGS, and SSG) were obtained by FT IR 8201 pc spectrophotometer by adopting $\mathrm{KBr}$ pellet method. The obtained IR graphs were given in graph no. 1 to 4 . IR spectra revealed that the Ofloxacin peaks in different carriers are similar to that Ofloxacin. IR spectral analysis ruled out the possibility of interaction between Ofloxacin and carriers (.PVPP, PGS, and SSG) ${ }^{9-11}$.

First order kinetic analysis of in-vitro Release Rates of Fast dissolving tablets of Ofloxacin

The results of in vitro release profile obtained for all the formulations were plotted in modes of data treatment as follows. First order kinetic model - Log cumulative percent drug remaining versus $\mathrm{T}$.

Preparation of Ofloxacin Fast Dissolving Tablets by Direct Compression Involves the Following Steps

- Blending

- Compression 
Blending

Procedure for preparation of mixed blend of drug and excipients

All ingredients were mixed as per the formula given in Table 3. Ofloxacinmannitol and MCC were triturated thoroughly in a glass mortar using a pestle. Super disintegrant were incorporated in the powder mix. And finally magnesium stearate and talc were added as lubricant. Control tablet was prepared without any super disintegrant.

Table 3: Formulation of Ofloxacin Fast dissolving tablets by Direct Compression

\begin{tabular}{|c|c|c|c|c|c|c|c|c|c|c|}
\hline \multirow{2}{*}{ S. No } & \multirow{2}{*}{ Ingredients } & \multicolumn{9}{|c|}{ Amount of ingrediants in Mg/Tablet } \\
\cline { 3 - 11 } & & $\mathbf{F}_{\mathbf{1}}$ & $\mathbf{F}_{\mathbf{2}}$ & $\mathbf{F}_{\mathbf{3}}$ & $\mathbf{F}_{\mathbf{4}}$ & $\mathbf{F}_{\mathbf{5}}$ & $\mathbf{F}_{\mathbf{6}}$ & $\mathbf{F}_{\mathbf{7}}$ & $\mathbf{F}_{\mathbf{8}}$ & $\mathbf{F}_{\mathbf{9}}$ \\
\hline 1 & Ofloxacin & 100 & 100 & 100 & 100 & 100 & 100 & 100 & 100 & 100 \\
\hline 2 & PGS & 24 & 36 & 48 & - & - & - & - & - & - \\
\hline 3 & SSG & - & - & - & 24 & 36 & 48 & - & - & - \\
\hline 4 & PVPP & - & - & - & - & - & - & 24 & 36 & 48 \\
\hline 5 & Mannitol & 164 & 152 & 140 & 164 & 152 & 140 & 164 & 152 & 140 \\
\hline 6 & $\begin{array}{c}\text { Microcrystalline } \\
\text { cellulose }\end{array}$ & 147 & 147 & 147 & 147 & 147 & 147 & 147 & 147 & 147 \\
\hline 7 & Magnisium stearate & 20 & 20 & 20 & 20 & 20 & 20 & 20 & 20 & 20 \\
\hline 8 & Talk & 20 & 20 & 20 & 20 & 20 & 20 & 20 & 20 & 20 \\
\hline 9 & Purified water & q.s & q.s & q.s & q.s & q.s & q.s & q.s & q.s & q.s \\
\hline
\end{tabular}

\section{Compression}

Mixed Blends were compressed by direct compression method using Rimek Minipress I

\section{Post Compression Parameters Weight variation}

The U.S.P. weight variation test was run by weighing 10 tablets and then the average weight was determined. All the 10 tablets were weighed individually and compared with the average weight as given in Table 5 .

\section{Drug content}

Five tablets were selected from each batch. The tablets were assayed individually by extracting the drug from the tablets using distilled water. The drug samples were analyzed by measuring the absorption at $287 \mathrm{~nm}$ by using Jasco V 530 UV-visible spectrophotometer. The results were shown in Table 6.

\section{Friability}

The friability test was performed for all the formulated ofloxacin tablets. Ten tablets were taken and their weight was determined. Then they were placed in the friabilator and allowed to make 100 revolutions. The tablets were then dedusted and reweighed. The percentage weight loss were calculated and given in Table 6 .

\section{Hardness}

Pfizer hardness tester was used for measuring the hardness of the formulated Ofloxacin fast dissolving tablets. From each batch five tablets were taken and subjected to test. The mean of the five tablets were calculated and the results were given in the Table 6.

\section{Disintegration}

The U.S.P. device to test disintegration uses six glass tubes that are 3" long, open at the top, and held against 10" screen at the bottom end of the basket rack assembly. One tablet is placed in each tube and the basket rack is positioned in 1 liter beaker of distilled water at $37+2{ }^{\circ} \mathrm{C}$, such that the tablets remain below the surface of the liquid on their upward movement and descend not closer than $2.5 \mathrm{~cm}$ from the bottom of the beaker. The disintegration time was recorded. The results were given in Table 6 .

\section{Wetting Time}

The wetting time of the tablets was measured using a simple procedure. Five circular tissue papers of $10 \mathrm{~cm}$ diameter were placed in a Petri dish containing water $(6 \mathrm{ml})$. A tablet was carefully placed on the surface of tissue paper. The time required for water to reach the upper surface of the tablet was noted as the wetting time. The results were given in Table 6 .

\section{Water Absorption Ratio}

A small piece of tissue paper folded twice was placed in a small Petri dish containing water. A tablet was put on the paper and the time required for complete wetting was measured. The wetted tablet was then reweighed. Water absorption ratio, $\mathrm{R}$ was determined by using following formula and results were given in Table 6 .

$$
\mathrm{R}=10 \times \mathrm{W}_{\mathrm{a}}-\mathrm{W}_{\mathrm{b}}
$$

$\mathrm{W}_{\mathrm{b}}$ is the weight of tablet before water absorption; $\mathrm{W}_{\mathrm{a}}$ is the weight of tablet after water absorption

\section{Dissolution studies}

Dissolution was carried out by using Electro lab dissolution apparatus (USP XXI) by paddle method using $900 \mathrm{ml}$ of distilled water as the medium and rotating the paddle at 50 rpm for 10 minutes. The temperature of dissolution medium was maintained at $37 \pm 2^{\circ} \mathrm{c}$. Aliquot samples were withdrawn at different time intervals of $0,2,4,6,8$ and 10 minutes. And it was replaced by adding equal volumes of fresh dissolution medium. The samples were suitably diluted and absorbance of the solution was determined at $287 \mathrm{~nm}$ by using Jasco V $530 \mathrm{UV}$-visible spectrophotometer. The percentage of Ofloxacin dissolved from tablet was calculated and the graph was plotted between times vs. \% of Ofloxacin dissolved. The results were given in Table 7 and graph $9^{12}$. 

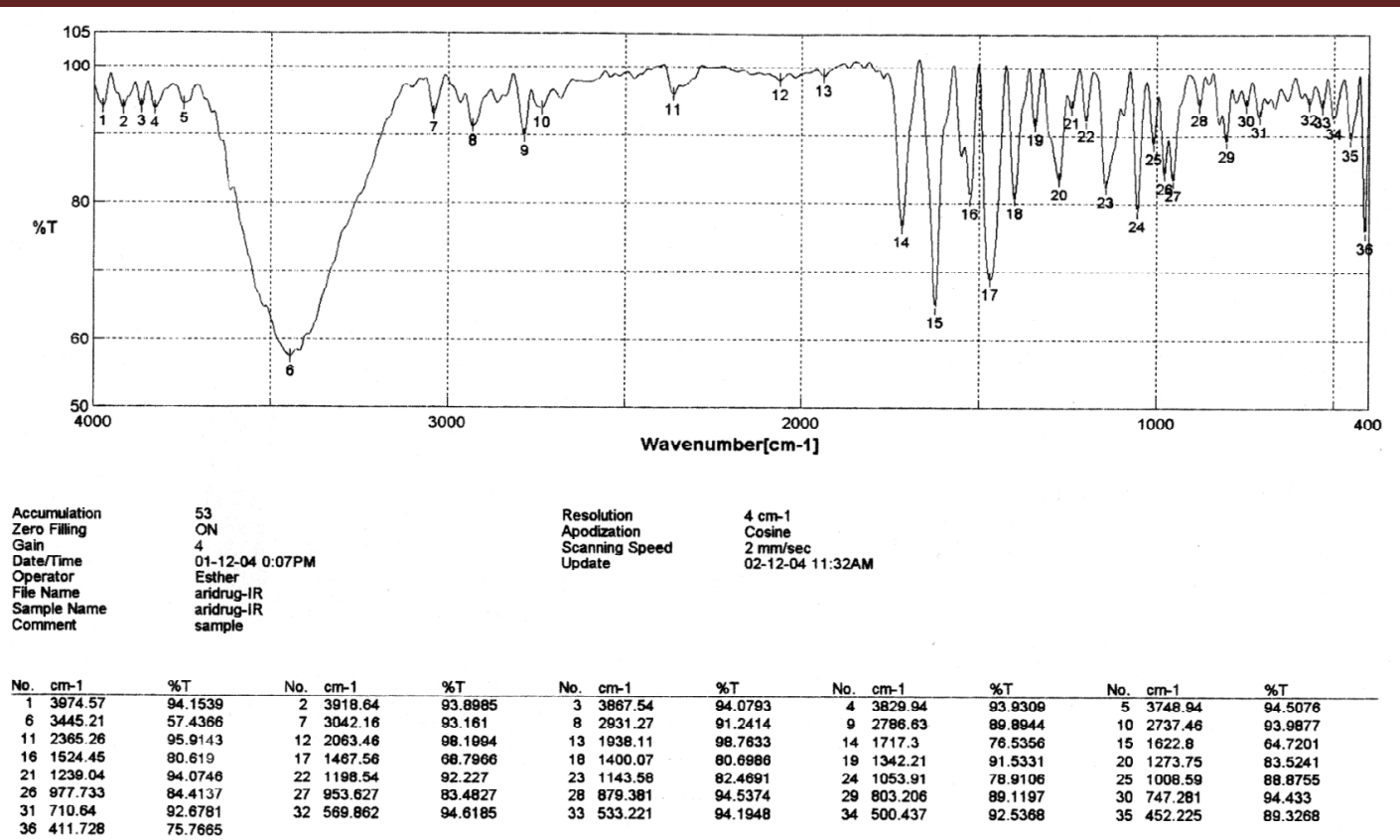

Figure 1: FTIR spectra of pure Ofloxacin
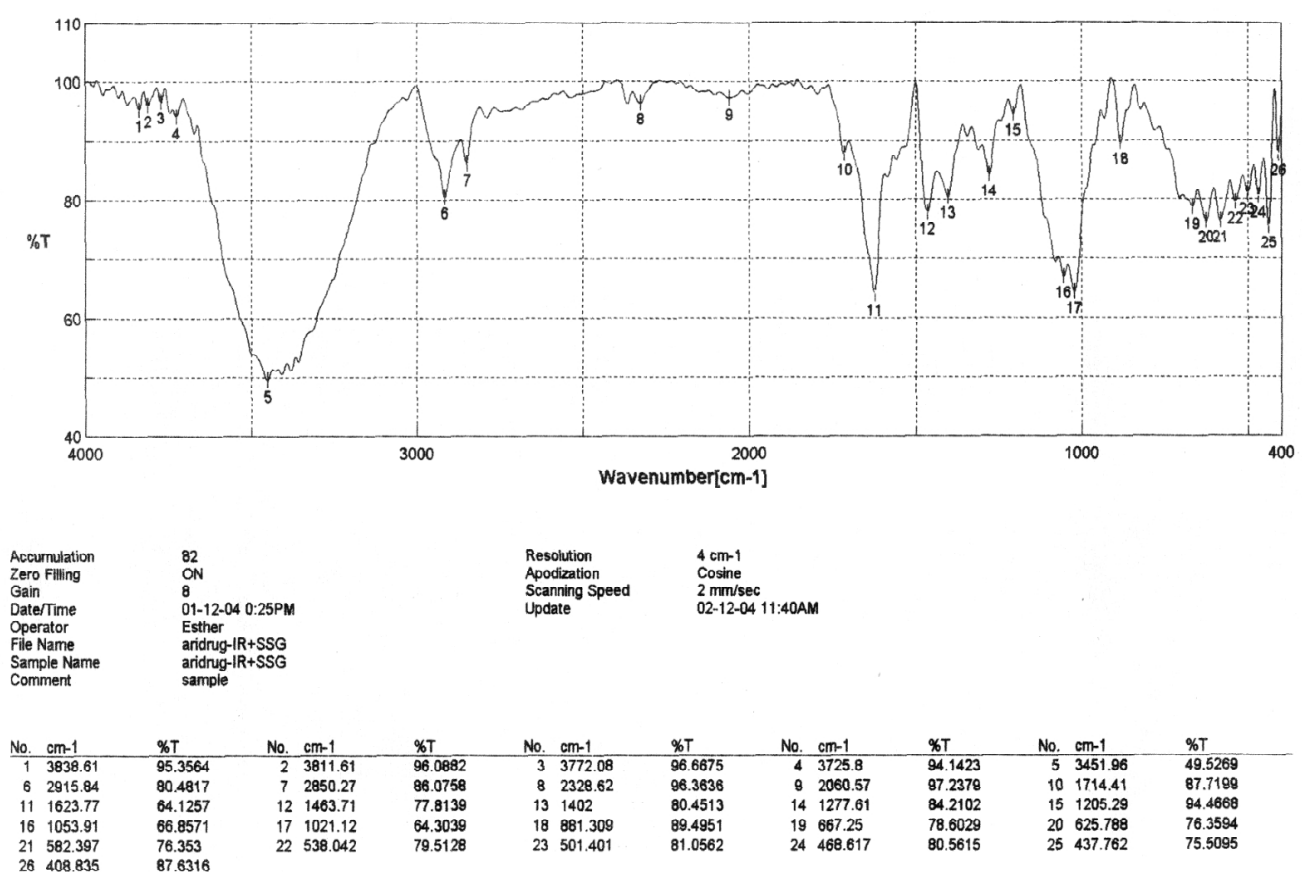

Figure 2: FITR spectra of ofloxacin with sodium starch glycolate 

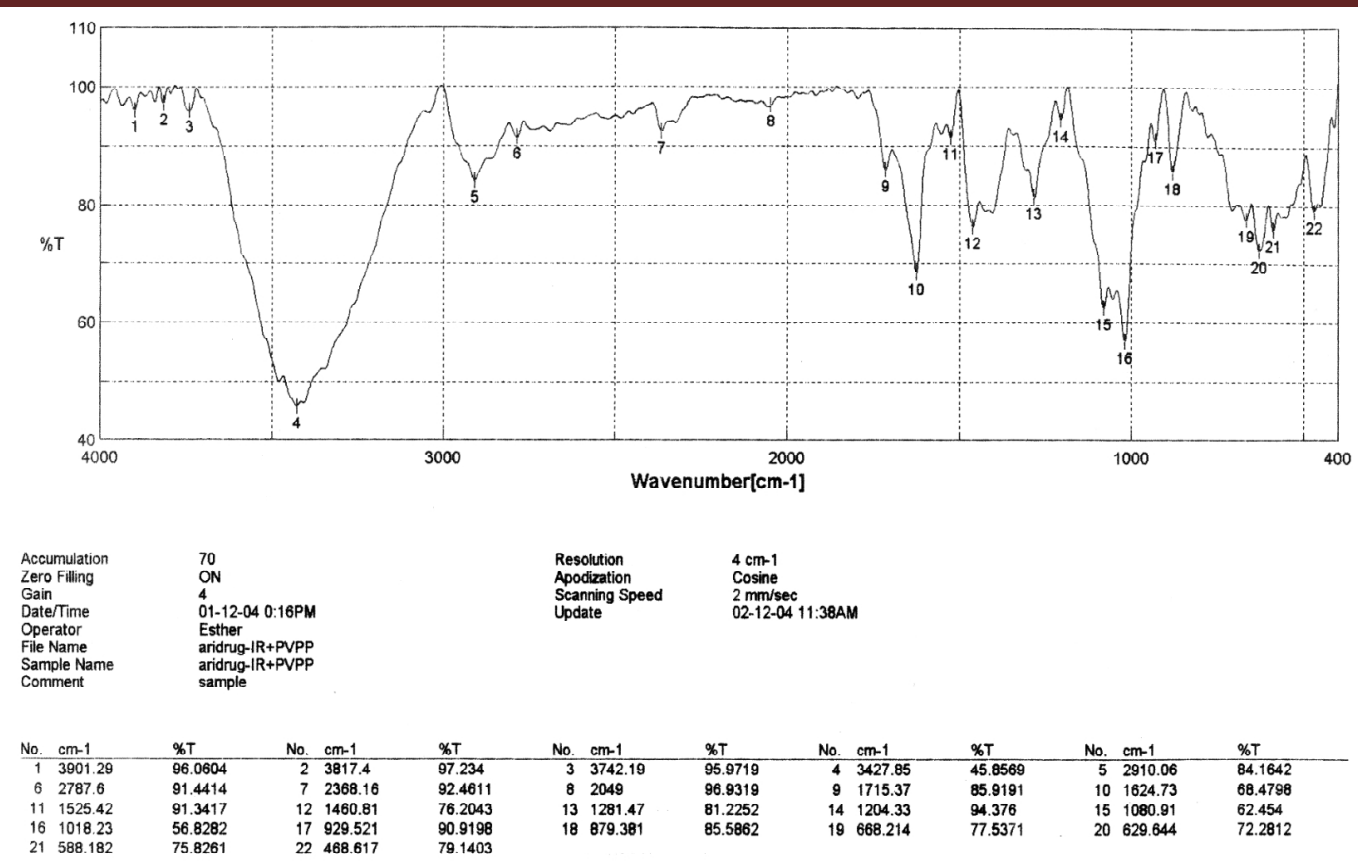

Figure 3: FTIR spectra of Ofloxacin and Polyvinylpolypyrrolidine
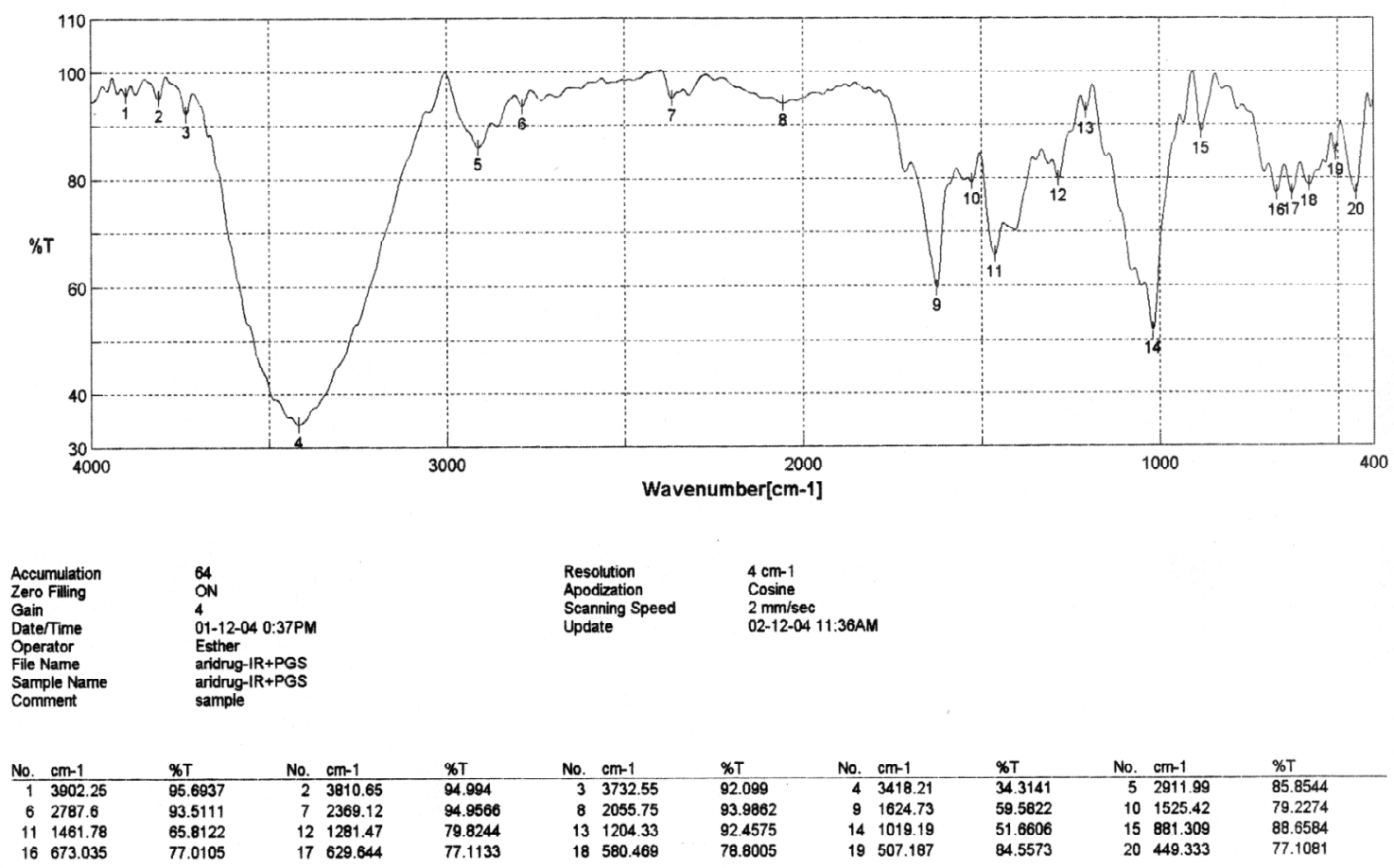

Figure 4: FTIR spectra of Ofloxacin and Pregelatinised starch

Table 4: Data for pre-compression parameters ofcontroland tablet formulations $\left(F_{1}-F_{9}\right)$

\begin{tabular}{|c|c|c|c|c|c|c|}
\hline Formulation code & Angle of repose $(\theta)$ & Bluk density $\left(\mathrm{g} / \mathrm{cm}^{3}\right)$ & Tapped density $\left(\mathrm{g} / \mathrm{cm}^{3}\right)$ & Carr's index (\%) & Hausner Ratio & Flow property \\
\hline Control (C) & $28 \pm 0.04$ & 0.59 & 0.69 & 14.49 & 1.16 & Good \\
\hline $\mathrm{F}_{1}$ & $29.2 \pm 0.03$ & 0.58 & 0.69 & 14.7 & 1.15 & Good \\
\hline$F_{2}$ & $29.6 \pm 0.04$ & 0.60 & 0.68 & 13.6 & 0.88 & Good \\
\hline $\mathrm{F}_{3}$ & $28 \pm 0.02$ & 0.57 & 0.67 & 14.9 & 1.3 & Good \\
\hline$F_{4}$ & $28.85 \pm 0.02$ & 0.57 & 0.66 & 13.63 & 1.15 & Good \\
\hline $\mathrm{F}_{5}$ & $30.5 \pm 0.01$ & 0.58 & 0.68 & 14.3 & 1.17 & Good \\
\hline $\mathrm{F}_{6}$ & $27 \pm 0.07$ & 0.56 & 0.65 & 13.9 & 1.16 & Good \\
\hline $\mathrm{F}_{7}$ & $25.8 \pm 0.03$ & 0.55 & 0.64 & 14.5 & 1.16 & Good \\
\hline$F_{8}$ & $26 \pm 0.02$ & 0.57 & 0.66 & 13.6 & 1.16 & Good \\
\hline $\mathrm{F}_{9}$ & $27.0 \pm .04$ & 0.56 & 0.65 & 13.8 & 1.32 & Good \\
\hline
\end{tabular}


Table 5: Weight variation data of control and tablet formulations $\left(F_{1}-F_{9}\right)$

\begin{tabular}{|c|c|c|c|}
\hline S. No & Product code & Average weight (mg) & Weight range of tablets (mg) \\
\hline 1 & Control (C) & 478 & $471-478$ \\
\hline 2 & $\mathrm{~F}_{1}$ & 476 & $473-479$ \\
\hline 3 & $\mathrm{~F}_{2}$ & 477 & $472-477$ \\
\hline 4 & $\mathrm{~F}_{3}$ & 475 & $471-477$ \\
\hline 5 & $\mathrm{~F}_{4}$ & 480 & $470-478$ \\
\hline 6 & $\mathrm{~F}_{5}$ & 478 & $472-479$ \\
\hline 7 & $\mathrm{~F}_{6}$ & 476 & $472-480$ \\
\hline 8 & $\mathrm{~F}_{7}$ & 479 & $471-4780$ \\
\hline 9 & $\mathrm{~F}_{8}$ & 474 & $470-476$ \\
\hline 10 & $\mathrm{~F}_{9}$ & 479 & $472-479$ \\
\hline
\end{tabular}

Table 6: Data for post compression parameters of control and tablet formulations $\left(F_{1}-F_{9}\right)$

\begin{tabular}{|c|c|c|c|c|c|c|}
\hline Product code & $\begin{array}{l}\text { Disintegrating } \\
\text { time (sec) }\end{array}$ & \begin{tabular}{|c|c|} 
Friability \\
(\% of weight loss)
\end{tabular} & $\begin{array}{l}\text { Hardness } \\
\left(\mathrm{kg} / \mathrm{cm}^{2}\right)\end{array}$ & $\begin{array}{l}\text { Wetting time } \\
\text { (sec) }\end{array}$ & $\begin{array}{c}\text { Water absorption ratio } \\
(\%)\end{array}$ & $\begin{array}{c}\text { Drug content uniformity } \\
(\%)\end{array}$ \\
\hline Control (C) & $1200 \pm 15$ & 0.5 & $3.4 \pm 1$ & $4800 \pm 7$ & 19 & 99.9 \\
\hline $\mathrm{F}_{1}$ & $63 \pm 4$ & 0.6 & $3.5 \pm 1$ & $135 \pm 3$ & 40.3 & 99.1 \\
\hline $\mathrm{F}_{2}$ & $53 \pm 2$ & 0.56 & $3.2 \pm 2$ & $108 \pm 3$ & 43 & 98.4 \\
\hline $\mathrm{F}_{3}$ & $45 \pm 2$ & 0.50 & $3.4 \pm 2$ & $90 \pm 2$ & 52.2 & 101.7 \\
\hline $\mathrm{F}_{4}$ & $54 \pm 3$ & 0.57 & $3.6 \pm 1$ & $115 \pm 3$ & 46.5 & 102 \\
\hline $\mathrm{F}_{5}$ & $49 \pm 1$ & 0.71 & $3.2 \pm 3$ & $95 \pm 3$ & 53.1 & 99.8 \\
\hline $\mathrm{F}_{6}$ & $40 \pm 2$ & 0.60 & $3.3 \pm 2$ & $82 \pm 2$ & 55.7 & 100.2 \\
\hline $\mathrm{F}_{7}$ & $15 \pm 2$ & 0.66 & $3.1 \pm 2$ & $33 \pm 2$ & 66 & 100 \\
\hline $\mathrm{F}_{8}$ & $12 \pm 1$ & 0.71 & $3.0 \pm 3$ & $23 \pm 2$ & 69.7 & 97.8 \\
\hline $\mathrm{F}_{9}$ & $8 \pm 2$ & 0.63 & $3.3 \pm 1$ & $4.3 \pm 0.3$ & 64.3 & 101.5 \\
\hline
\end{tabular}

Table 7: Dissolution data for control and tablet formulations $\left(F_{1}-F_{9}\right)$

\begin{tabular}{|c|c|c|c|c|c|c|c|c|c|c|c|}
\hline \multirow[t]{2}{*}{ S. No } & \multirow{2}{*}{$\begin{array}{l}\text { Time in } \\
\text { minute }\end{array}$} & \multicolumn{10}{|c|}{$\%$ of drug release } \\
\hline & & control & $\mathbf{F}_{1}$ & $\mathbf{F}_{2}$ & $\mathbf{F}_{3}$ & $\mathbf{F}_{4}$ & $\mathbf{F}_{5}$ & $F_{6}$ & $\mathbf{F}_{7}$ & $\mathbf{F}_{8}$ & $\mathbf{F}_{9}$ \\
\hline 1 & 0 & 0 & 0 & 0 & 0 & 0 & 0 & 0 & 0 & 0 & 0 \\
\hline 2 & 2 & 6.8 & 47.3 & 55.4 & 62.0 & 47.9 & 59.5 & 63.6 & 68.5 & 67.5 & 71.4 \\
\hline 3 & 4 & 7.7 & 51.2 & 59.7 & 67.2 & 52.3 & 61.8 & 67.7 & 71.5 & 74.0 & 74.7 \\
\hline 4 & 6 & 13.8 & 54.6 & 66.0 & 69.1 & 56.4 & 67.5 & 72.0 & 76.8 & 76.2 & 79.5 \\
\hline 5 & 8 & 17.5 & 59.2 & 71.1 & 75.6 & 62.1 & 73.7 & 76.8 & 77.9 & 78.5 & 85.0 \\
\hline 6 & 10 & 23.6 & 66.7 & 76.5 & 77.9 & 68.5 & 75.8 & 79.5 & 79.5 & 82.4 & 87.0 \\
\hline
\end{tabular}

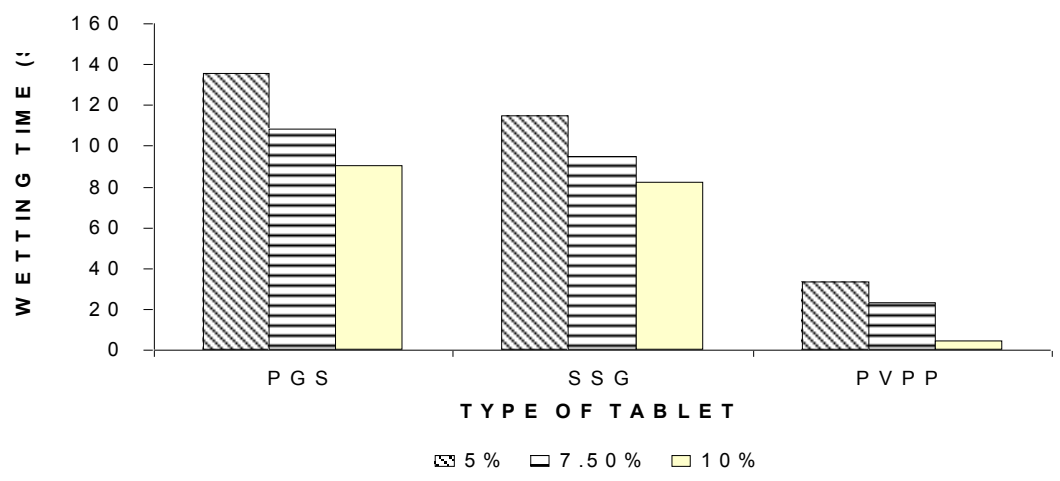

Figure 5: Wetting time for various Ofloxacin Fast dissolving tablets

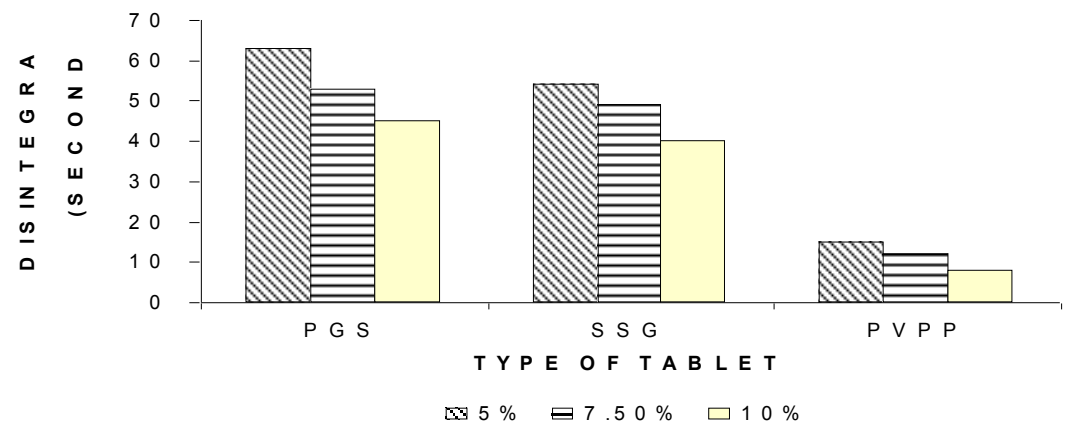

Figure 6: Disintegrating time for various Ofloxacin Fast dissolving tablets 


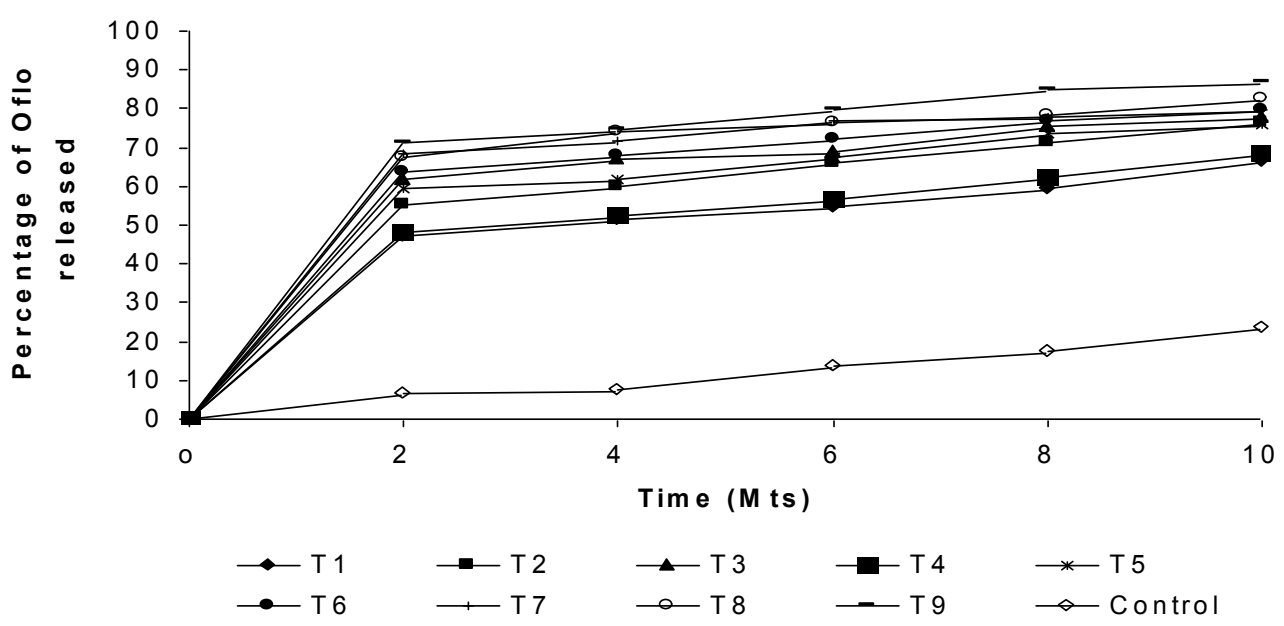

Figure 7: Comparative in-vitro drug release profiles of Ofloxacin control and tablet formulations $\left(F_{1}-F_{9}\right)$

Table 8: moisture uptake studies Data for tablet formulations $\left(F_{3}, F_{6}, F_{9}\right)$ at Zero month

\begin{tabular}{|c|c|c|}
\hline Product code & Hardness $\mathbf{( K g / \mathbf { c m } ^ { 2 } )}$ & Disintegration Time ( seconds) \\
\hline F3 & $3.4 \pm 2$ & $45 \pm 2$ \\
F6 & $3.3 \pm 1$ & $40 \pm 2$ \\
F9 & $3.3 \pm 2$ & $8 \pm 1$ \\
\hline
\end{tabular}

Table 9: Moisture uptake studies Data for tablet formulations $\left(F_{3}, F_{6}, F_{9}\right)$ after three months

\begin{tabular}{|c|c|c|c|}
\hline $\begin{array}{c}\text { Product } \\
\text { code }\end{array}$ & $\begin{array}{c}\text { \% of moisture } \\
\text { absorption }\end{array}$ & $\begin{array}{c}\text { Effect on Hardness } \\
\left(\mathbf{K g} / \mathbf{c m}^{2}\right)\end{array}$ & $\begin{array}{c}\text { Effect on Disintegration } \\
\text { ( seconds) }\end{array}$ \\
\hline F3 & 1.4 & $2.8 \pm 1$ & $36 \pm 1$ \\
F6 & 1.0 & $3.0 \pm 1$ & $38 \pm 1$ \\
F9 & 1.2 & $2.7 \pm 1$ & $6 \pm 2$ \\
\hline
\end{tabular}

Table 10: First order rate constant for Ofloxacin Fast dissolving tablets $\left(F_{1}-F_{9}\right)$ and control tablet $(C)$

\begin{tabular}{|c|c|c|}
\hline S. No & Solid Dispersion & K ( $\left.\mathbf{m i n}^{-1}\right)$ \\
\hline 1 & Control (C) & 0.0004 \\
\hline 2 & F1 & 0.038 \\
\hline 3 & F4 & 0.051 \\
\hline 4 & F7 & 0.07 \\
\hline 5 & F2 & 0.053 \\
\hline 6 & F5 & 0.065 \\
\hline 7 & F8 & 0.077 \\
\hline 8 & F3 & 0.067 \\
\hline 9 & F6 & 0.076 \\
\hline 10 & F9 & 0.111 \\
\hline
\end{tabular}

\section{RESULTS AND DISCUSSION}

Studies were undertaken on the preparation and evaluation of Fast dissolving tablets of Ofloxacin with a view to develop rapid disintegration in mouth and fast dissolution. Nine batches $\left(\mathrm{F}_{1}-\mathrm{F}_{9}\right)$ of Ofloxacin fast dissolving Tablets were prepared with three super disintegrants each at three concentrations $(5 \%, 7.5 \%$ and $10 \%)$ by direct compression technique. The same way one control batch (C) is prepared without any super disintegrant. Microcrystalline cellulose, mannitol, magnesium stearate and talc are used as excipients for the above formulations.

\section{Compatibility Studies}

The IR Spectrum of pure Ofloxacin drug was compared with the IR spectrum of formulated Ofloxacin fast dissolving tablets $\left(\mathrm{F}_{1}, \mathrm{~F}_{4}\right.$ and $\left.\mathrm{F}_{7}\right)$. The IR spectrums of the above series of formulation are matched with the IR spectrum of pure Ofloxacin. (Figure 1-4) There is no appearance or disappearance of any characteristics peaks, this shows that there is no interaction between the drug and excipients used in the tablets.

\section{Flow Properties}

Powder blend of drug and excipients were prepared and evaluated for angle of repose, bulk density, tapped density and percentage compressibility (Table 4). The angle of repose was found to be in the range of $26^{0}-31^{\circ}$. Flow properties of prepared powdered blend were found to be good.

\section{Evaluation of Tablets}

All the batches of Ofloxacin fast dissolving tablets fulfilled official requirements of uniformity of weight. All the tablets prepared were found to contain the medicament within $100 \pm$ $5 \%$ of labeled claim. Hardness of the tablets in all the batches was found to be in the range of $3.0-3.6 \mathrm{~kg} / \mathrm{cm}^{2}$ and was satisfactory. The percentage weight loss in the friability test was found to be less than $1 \%$ in all the batches (Table 6). Thus all the formulated Ofloxacin fast dissolving tablets employing super disintegrants were found to be good quality fulfilling the official and other general requirements of compressed tablets. All the formulated Ofloxacin fast dissolving tablets employing PVPP, PGS, SSG disintegrated within 60 seconds fulfilling official requirements for compressed tablets, whereas the disintegrating time of control tablet more when compared to the formulated tablets (Table 6). This can be attributed to the extent of water uptake and consequently the strong swelling power of this super disintegrant causing sufficient hydrodynamic pressure to induce complete disintegration. This can be correlated to tablet matrix pore size distribution created by the use of super disintegrant. Higher levels of disintegrant probably made 
large pores with continuous network or skeleton providing enough pressure within a matrix for fast disintegration.

\section{In Vitro Release}

In vitro dissolution profiles of Ofloxacin fast dissolving tablets and controlled tablets are shown in (Table 7 and Figure 9). The dissolution of the medicament from all the formulated batches as well as controlled batch followed first order kinetics (Table 10). Among the batches formulated, $\mathrm{F}_{9}$ released the $87 \%$ of the medicaments at the end of 10 minutes. All the other formulated tablets $\left(\mathrm{F}_{1}-\mathrm{F}_{8}\right)$ released almost $70-80 \%$ at the end of 10 minutes. The orders of increase in dissolution by various super disintegrants are as follows $\left(\mathrm{F}_{7}-\mathrm{F}_{9}\right)>\left(\mathrm{F}_{4}-\mathrm{F}_{6}\right)>\left(\mathrm{F}_{1}-\mathrm{F}_{3}\right)$

\section{Wetting Time and Water Absorption Ratio}

Wetting time and water absorption ratio (Table 6) of all the formulated batches is an important criteria for the faster disintegrant as well as dissolution of the drug. Hence, all the formulated batches having faster disintegration and dissolution compared with control batch.

\section{Moisture Uptake Studies}

The moisture uptake studies carried out for the three batches $\left(F_{3}, F_{6}\right.$ and $\left.F_{9}\right)$ of the formulated tablets. The average equilibrium moisture uptake by above series of Ofloxacin fast dissolving tablets at $79.3 \% \mathrm{RH}$ was $1.4,1.0$ and 1.2 respectively (Table 8 and 9). Hence, the formulated batches need the protection from humidity which calls for specialized product packaging.

\section{CONCLUSION}

Attempts were made to study the disintegration and dissolution of Ofloxacin using three super disintegrants were carried out. Chemical incompatibility studies confirmed that there is no interaction between drug and excipients used in the formulations. The flow properties of the powdered blend for all the batches were found to be good and free flowing; the weight variation, hardness and friability of all the formulated tablets within the specified requirements. The disintegration times for the formulated tablets are less than the control tablets. In vitro dissolution studies shows higher percentage of drug release for all the formulated batches $\left(\mathrm{F}_{1}\right.$ -
$\mathrm{F}_{9}$ ) and compared with controlled batch. The improvement in the dissolution may be due to higher water absorption and swelling property of super disintegrants. So the improve in the rate in disintegration of tablets, thereby increase the dissolution. The more percentage of drug released can be seen in the formulation containing PVPP $\left(\mathrm{F}_{7}-\mathrm{F}_{9}\right)$, when compared with the other super disintegrants. The $\%$ of drug released in the case of PVPP $\left(\mathrm{F}_{9}\right)$ was more when compared with the other two concentrations $\left(\mathrm{F}_{7}-\mathrm{F}_{8}\right)$. Hence PVPP $\left(\mathrm{F}_{9}\right)$ was found to be better super disintegrant for the formulation of ofloxacin fast dissolving tablets when compare to other super disintegrants used in the study.

\section{ACKNOWLEDGEMENT}

The authors thank Dr. Reddy's laboratories, Hyderabad, India for providing ofloxacin as gift sample for this work. The authors are also thankful to Dr. Sridhar bandari Rand D Manager, Hetero drugs ltd, Hyderabad, India for their valuable suggestions and support throughout my research work. The authors also thankful to Head of the institutions and DR. M.S Halith, H.O.D, K.M College of pharmacy, Madurai, India for providing required facilities to carry out this research work.

\section{REFERENCES}

1. Leon Lachmann, Herbert A Lieberman, Joseph L Kanig. The theory and practice of Industrial Pharmacy. CBS publishers; 2009. p. 293-303

2. Reddy LH. Fast Dissolving Drug Delivery Systems: A Review of the literature. IJPS July 2002; 331-336.

3. European Pharmacopoeia. Council of Europe 2004; (1): 628.

4. Kuchekar BS, Badhan Atul C, Mahajan HS. Mouth Dissolving Tablets: A Novel Drug Delivery System. Pharma Times 2003; (35).

5. Nayak SM. Design and optimization of fast dissolving tablets for promethazine theoclate. Indian drugs September 2004; 41(9): 554-556.

6. Kasture VS. Spectrophotometric method for simultaneous estimation of ofloxacin and ornidazole in tablet dosage form. Indian drugs; 2004. p. 51-53.

7. Mathur SC. Spectrophotometric method for estimation of ofloxacin tablet. Indian drugs; 1992. p. 376-377.

8. Mathur SC. Spectroflourimetry estimation of ofloxacin tablets. Eastern pharmacist; 1992. p. 117-118.

9. British Pharmacopoeia. Keats publishers 2003; (1): 1357-1358

10. File: //A:/ floxin tablets drug information floxin tablets. htm

11. File: //A:/ RX med pharmaceutical information - floxin. htm

12. File: //A:/ ofloxacin -information women's health and medical concerning women's health. Htm.

Cite this article as:

Shivaramakrishna Baddam, Sreedhar Bandari, G.B Chaithanya. Formulation and evaluation of fast dissolving tablets of ofloxacin by direct compression method. Int. Res. J. Pharm. 2013; 4(11):79-86 http://dx.doi.org/ $\underline{10.7897 / 2230-8407.041118}$ 